\title{
To target or not to target APRIL in systemic lupus erythematosus: that is the question!
}

\author{
Jacques Morel ${ }^{* 1,2,3}$ and Michael Hahne $e^{2,3,4}$ \\ See related research by Treamtrakanpon et al., http://arthritis-research.com/content/14/6/R252
}

\begin{abstract}
Among the cytokines that regulate B-cell homeostasis are the TNF-like ligands B-lymphocyte stimulator (BLyS; also B-cell activation factor) and a proliferationinducing ligand (APRIL). BLyS and APRIL share two receptors; that is, B-cell maturation antigen and transmembrane activator and CAML interactor. Therapeutic approaches using biologics are limited for treatment of lupus patients. One previously approved drug is belimumab, which antagonizes the B-cell stimulator BLyS. Atacicept, another biologic inhibiting BLyS and APRIL, was terminated for serious adverse events - raising the question of whether APRIL should be neutralized in autoimmune diseases.
\end{abstract}

Treamtrakanpon and coworkers analyzed B-lymphocyte stimulator (BLyS; also B-cell activation factor) and a proliferation-inducing ligand (APRIL) expression in patients with lupus nephritis and observed a correlation with renal disease activity and APRIL serum levels [1]. In addition, the authors describe that, upon treatment with immunosuppressors, nonresponding patients had higher APRIL serum levels. They thus concluded that APRIL could be a potential biomarker for predicting difficult-totreat cases of lupus nephritis, and propose the use of APRIL antagonists such as atacicept for treatment of lupus nephritis patients with high APRIL serum levels.

These conclusions might be premature, as Treamtrakanpon and coworkers have not found a correlation between the level of APRIL in kidney tissue and renal disease activity. Another hypothesis could be that APRIL has a protective effect in autoimmune diseases. Indeed, the crucial role of BLyS in B-cell maintenance became

\footnotetext{
*Correspondence: j-morel@chu-montpellier.fr

'Department of Rheumatology, CHU Lapeyronie, 191 avenue du Doyen Gaston, Giraud, 34295 Montpellier, Cedex 5, France

Full list of author information is available at the end of the article
}

evident by the analysis of BLyS-deficient mice displaying lower numbers of mature B cells and of BLyS transgenic mice developing severe B-cell hyperplasia. Although APRIL can trigger different B-cell responses in vitro, including proliferation and survival of human and murine $\mathrm{B}$ cells, it is less critical than BLyS in B-cell maintenance as APRIL knockout and transgenic mice reveal no gross abnormalities in lymphoid homeostasis [2]. In fact, APRIL was found to modulate specific B-cell responses such as IgA isotype switching, increased IgM secretion and B1 cell activity.

Meanwhile, BLyS is an established promoter of B-celltriggered autoimmmune diseases such as systemic lupus erythematosus and rheumatoid arthritis, whereas the role of APRIL in these pathologies is rather controversial. Neutralizing BLyS with the mAb belimumab displayed a modest, although statistically significant, therapeutic effect in systemic lupus erythematosus [3,4]. But blocking both BLyS and APRIL with atacicept (TACI-Fc) was associated with a pronounced reduction of immunoglobulins, and occurrence of serious infections led to a premature termination of a phase II/III trial in lupus nephritis [5]. The combination of mycofenolate mofetil with atacicept may have contributed to the decrease of immunoglobulins. However, atacicept combined with another drug such as methotrexate in patients with rheumatoid arthritis was also associated with a significant reduction of immunoglobulins (especially IgM). In this autoimmune disease, atacicept failed to demonstrate efficacy on American College of Rheumatology 20 criteria [6]. In contrast, administration of belimumab showed a modest but significant efficacy using the same evaluation criteria in rheumatoid arthritis [7].

These findings suggest distinct roles for BLyS and APRIL in lupus and other B-cell-mediated autoimmune diseases. Elevated serum levels are found for both cytokines in lupus patients, and for BLyS there is a consensus in the literature that this reflects its diseasepromoting activity. Elevated APRIL serum levels, however, have been - depending on the respective study either positively or negatively correlated with disease features [8]. One possible explanation for this discrepancy 
could be differences in the patient cohorts analyzed. A recent study by Jacob and colleagues analyzed a murine lupus model in APRIL-deficient mice and observed elevated numbers of splenocytes, increased autoantibody production and a tendency towards increased IgG production [9]. Notably, ectopic APRIL expression does not result - in contrast to BLyS transgenic mice - in lupus-like symptoms. In fact, we found that APRIL does dampen collagen-induced arthritis, the most common mouse model for human arthritis [10].

Experimental mouse models for autoimmune diseases obviously cannot entirely mimic human diseases. Nevertheless, in vivo data are accumulating that do not support a disease-supporting role for APRIL in B-cell-mediated autoimmunity. The study by Treamtrakanpon and colleagues is putting forward the need to better elucidate the role of APRIL in B-cell-driven diseases before concluding a therapeutic approach.

\section{Abbreviations}

APRIL, a proliferation-inducing ligand; BLyS, B-lymphocyte stimulator; mAb, monoclonal antibody; TNF, tumor necrosis factor.

\section{Competing interests}

The authors declare that they have no competing interests.

\section{Author details}

'Department of Rheumatology, CHU Lapeyronie, 191 Avenue du Doyen Gaston, Giraud, 34295 Montpellier, Cedex 5, France. IInstitut de Génétique Moléculaire de Montpellier, CNRS, UMR5535, 1919 route de Mende, 34293 Montpellier, France. ${ }^{3}$ Université Montpellier 1, 5 Boulevard Henri IV, 34000 Montpellier, Cedex 5, France. ${ }^{4}$ Université Montpellier 2, Place Eugène Bataillon, 34095 Montpellier, Cedex 5, France.

Published: 25 February 2013

\section{References}

1. Treamtrakanpon W, Tantivitayakul P, Benjachat T, Somparn P, Kittikowit W, Eiam-Ong S, Leelahavanichkul A, Hirankarn N, Avihingsanon Y: APRIL, a proliferation-inducing ligand, as a potential marker of lupus nephritis. Arthritis Res Ther 2012, 14:R252.
2. Stein JV, López-Fraga M, Elustondo FA, Carvalho-Pinto CE, Rodríguez D, Gómez-Caro R, De Jong J, Martínez-A C, Medema JP, Hahne M: APRIL modulates B and T cell immunity. J Clin Invest 2002, 109:1587-1598.

3. Manzi S, Sánchez-Guerrero J, Merrill JT, Furie R, Gladman D, Navarra SV, Ginzler EM, D'Cruz DP, Doria A, Cooper S, Zhong ZJ, Hough D, Freimuth W, Petri MA; BLISS-52 and BLISS-76 Study Groups: Effects of belimumab, a B lymphocyte stimulator-specific inhibitor, on disease activity across multiple organ domains in patients with systemic lupus erythematosus: combined results from two phase III trials. Ann Rheum Dis 2012, 71:1833-1838.

4. Navarra SV, Guzmán RM, Gallacher AE, Hall S, Levy RA, Jimenez RE, Li EK, Thomas M, Kim HY, León MG, Tanasescu C, Nasonov E, Lan JL, Pineda L, Zhong ZJ, Freimuth W, Petri MA; BLISS-52 Study Group: Efficacy and safety of belimumab in patients with active systemic lupus erythematosus: a randomised, placebo-controlled, phase 3 trial. Lancet 2011, 377:721-731.

5. Ginzler EM, Wax S, Rajeswaran A, Copt S, Hillson J, Ramos E, Singer NG: Atacicept in combination with MMF and corticosteroids in lupus nephritis: results of a prematurely terminated trial. Arthritis Res Ther 2012, 14:R33.

6. Genovese MC, Kinnman N, de La Bourdonnaye G, Pena Rossi C, Tak PP: Atacicept in patients with rheumatoid arthritis and an inadequate response to tumor necrosis factor antagonist therapy: results of a phase II, randomized, placebo-controlled, dose-finding trial. Arthritis Rheum 2011, 63:1793-1803.

7. McKay J, Chwalinska-Sadowska H, Boling E, Valente R, Limanni A, Racewicz A, Wierzbinska-Zarowny D, Fernandez V, Zhong J, Zilberstein M, et al.; LBRA01 Study Group: Belimumab, a fully human monoclonal antibody to B-lymphocyte stimulator, combined with standard care of therapy reduces the signs and symptoms of rheumatoid arthritis in a heterogeneous subject population. Arthritis Rheum 2005, 52:S710-S711.

8. Morel J, Roubille C, Planelles L, Rocha C, Fernandez L, Lukas C, Hahne M, Combe B: Serum levels of tumour necrosis factor family members a proliferation-inducing ligand (APRIL) and B lymphocyte stimulator (BLyS) are inversely correlated in systemic lupus erythematosus. Ann Rheum Dis 2009, 68:997-1002.

9. Jacob CO, Guo S, Jacob N, Pawar RD, Putterman C, Quinn WJ 3rd, Cancro MP, Migone TS, StohI W: Dispensability of APRIL to the development of systemic lupus erythematosus in NZM 2328 mice. Arthritis Rheum 2012, 64:1610-1619.

10. Fernandez L, Salinas GF, Rocha C, Carvalho-Pinto CE, Yeremenko N, Papon L, Medema JP, Combe B, Morel J, Baeten D, Hahne M: The TNF family member APRIL dampens collagen-induced arthritis. Ann Rheum Dis 2012. [Epub ahead of print]

doi:10.1186/ar4160

Cite this article as: Morel J, Hahne M: To target or not to target APRIL in systemic lupus erythematosus: that is the question! Arthritis Research \& Therapy 2013, 15:107. 